\title{
44 Fettgewebe als Syntheseort von Hormonen und Botenstoffen
}

\author{
(c) Springer-Verlag GmbH Deutschland, ein Teil von Springer Nature 2018 \\ D. Mathias, Fit und gesund von 1 bis Hundert \\ https://doi.org/10.1007/978-3-662-56307-6_44
}

Übergewicht bewirkt eine Vergrößerung der Fettzellen. Aus dem besonders problematischen Bauchfettgewebe werden erleichtert Fettsäuren und die unterschiedlichsten Zelltypen, die speziell in diesem Fettanteil vorkommen, freigesetzt. Diese bilden ihrerseits Dutzende Hormone, Zytokine und andere Botenstoffe mit weitreichenden systemischen Folgen.

Wichtige vom Fettgewebe gebildete bioaktive Stoffe sind u. a.:

- Adiponectin

- Angiotensin I und II

- Cholesterinester-Transfer-Protein

- Fetuin-A

- Insulin-like growth factor 1

- Interleukin 1, 6 und 8

- Leptin

- Östradiol

- Plasminogenaktivator-Inhibitor 1

- Prostacyclin

- Resistin

- Retinol-Bindungsprotein 4

- Stickstoffmonoxid

- Tumornekrosefaktor $\alpha$

- Vaspin

- Visfatin

Die vermehrte Bildung von Angiotensin im Fettgewebe ist z. B. eine der Ursachen dafür, dass ca. $50 \%$ der Übergewichtigen einen zu hohen Blutdruck haben. Wegen des höheren Östradiolspiegels übergewichtiger Frauen entwickeln diese eher als nor- malgewichtige Frauen Brust- und Gebärmutterkrebs (Neuhauser et al. 2015, s. auch $>$ Kap. 73), sind aber weniger osteoporosegefährdet ( $\downarrow$ Kap. 83). Hohe Leptinkonzentrationen können zur Degeneration der Gelenkmatrix und im Gefolge zu Gelenkschäden führen ( $\triangleright$ Kap. 63). Zu den wichtigsten, in zahlreichen großen internationalen Studien (Renehan et al. 2008; Strate et al. 2009; World Cancer Research Fund 2009; Yuan et al. 2013; Sorensen et al. 2014; Wada et al. 2014; Yingting et al. 2016) immer wieder bestätigten gesundheitlichen Risiken durch Übergewicht gehören darüber hinaus:

- Degenerative Gelenkerkrankungen

- Diabetes mellitus

- Divertikulitis

- Erhöhte Operationsrisiken

- Gallen- und Nierensteinbildung

- Gicht

- Herzinfarkt

- Nierenschäden

- Schlafapnoesyndrom

- Schlaganfall

- Venenleiden

- Vergrößerung des linken Vorhofs

- Vermehrung der linksventrikulären Muskelmasse

- Leukämie

- Multiples Myelom

- Non-Hodgkin-Lymphom

- Tumorbildungen der Schilddrüse, Speiseröhre, Gallenwege, Leber, Nieren, Eierstöcke, Prostata sowie des Darms 